\title{
artigo
}

Albertini, A.B.N.; Garcia, T.V.; Paulo, L.G.; Toledo, E.R.S.; Charlo, P.B.; Silva, M.;

Caracterização epidemiológica e sociodemográfica de acidentes de trânsito: uma revisão integrativa da literatura

\section{Caracterização epidemiológica e sociodemográfica de acidentes de trânsito: uma revisão integrativa da literatura}

\author{
Epidemiological and sociodemographic characterization of trafic accidentes: an integrative literature review \\ Caracterización epidemiológica y sociodemográfica de accidentes de tráfico: una revisión integrativa de la literatura
}

\begin{abstract}
RESUMO
Objetivou-se caracterizar o perfil sociodemográfico e epidemiológico das vítimas de acidentes de trânsito no Brasil. Método: Revisão Integrativa, realizada nas estratégias de busca SciELO Brasil - (Scientific Electronic Library Online), LILACS (Centro Latino-Americano de Informação em Saúde) e nas universidades brasileiras. Critérios de inclusão: artigos que apresentavam especificidade com o tema, que contivessem os descritores selecionados, publicados entre 2011 e 2019. E os de exclusão: artigos que não contemplavam os objetivos e anteriores a 2011. Resultados: De 52 artigos, restaram 20 como amostra final. Identificou-se que a maioria das vítimas são homens adultos jovens pertencentes a classe baixa, das regiões Nordeste e Norte e usuários de motocicleta. Os acidentes ocorrem mais comumente nos finais de semana e no período noturno, sendo a colisão frontal mais recorrente. Entre as principais causas está o fator humano. Conclusão: mediante esses resultados, pode-se afirmar a necessidade de melhorias na legislação e fiscalização do trânsito brasileiro.
\end{abstract}

DESCRITORES: Saúde Pública; Ferimentos e lesões; Acidente de trânsito.

\section{ABSTRACT}

The objective was to characterize the sociodemographic and epidemiological profile of victims of traffic accidents in Brazil. Method: Integrative review, carried out in the search strategies SciELO Brazil - (Scientific Electronic Library Online), LILACS (Latin American Center for Health Information) and in Brazilian universities. Inclusion criteria: articles that presented specificity to the theme, containing the selected descriptors, published between 2011 and 2019. And exclusion criteria: articles that did not contemplate the objectives and prior to 2011. Results: Of 52 articles, 20 remained as a final sample. It was identified that the majority of victims are young adult men belonging to the lower class, from the Northeast and North regions and motorcycle users. Accidents occur most commonly on weekends and at night, being the frontal collision the most frequent. Among the main causes is the human factor. Conclusion: based on these results, it is possible to affirm the need for improvements in Brazilian traffic legislation and enforcement.

DESCRIPTORS: Public Health; Wounds and injuries; Traffic accident.

\section{RESUMEN}

El objetivo fue caracterizar el perfil sociodemográfico y epidemiológico de las víctimas de accidentes de tránsito en Brasil. Método: Revisión integradora, realizada en las estrategias de búsqueda SciELO Brasil - (Biblioteca Electrónica Científica en línea), LILACS (Centro Latinoamericano de Información en Salud) y en universidades brasileñas. Criterios de inclusión: artículos que presentaron especificidad al tema, conteniendo los descriptores seleccionados, publicados entre 2011 y 2019. Y criterios de exclusión: artículos que no contemplaban los objetivos y anteriores a 2011. Resultados: De 52 artículos, 20 quedaron como muestra final. Se identificó que la mayoría de las víctimas son hombres adultos jóvenes que pertenecen a la clase baja, de las regiones del noreste y norte y usuarios de motocicletas. Los accidentes ocurren con mayor frecuencia los fines de semana y por la noche, con la colisión frontal más frecuente. Entre las principales causas se encuentra el factor humano. Conclusión: con base en estos resultados, es posible afirmar la necesidad de mejoras en la legislación y la aplicación de la ley de tránsito de Brasil.

DESCRIPTORES: Salud Pública; Heridas y lesiones; Accidente de tránsito.

RECEBIDO EM: 30/06/2020 APROVADO EM: 27/07/2020

\section{Ana Beatriz Nakayama Albertini}

Acadêmica do curso de Medicina do Centro Universitário de Maringá (UniCesumar), Maringá, Paraná, Brasil.

ORCID: 0000-0003-0158-221X 


\section{Taísa Vieira Garcia}

Acadêmica do curso de Medicina do Centro Universitário de Maringá (UniCesumar), Maringá, Paraná, Brasil. ORCID: 0000-0002-2641-7475

\section{Luiz Gustavo de Paulo}

Mestrando em Profissional em Gestão, Tecnologia e Inovação em Urgência e Emergência pela Universidade Estadual de Maringá (UEM), Docente do Curso de Medicina do Centro Universitário de Maringá UniCesumar, Maringá, Paraná, Brasil.

ORCID: 0000-0001-9090-7420

\section{Erika Rodrigues da Silva Toledo}

Mestrando em Profissional em Gestão, Tecnologia e Inovação em Urgência e Emergência pela Universidade Estadual de Maringá (UEM), Docente do Curso de Medicina do Centro Universitário de Maringá UniCesumar, Maringá, Paraná, Brasil.

ORCID: 0000-0002-4605-2426

\section{Patrícia Bossolani Charlo}

Doutorando em Enfermagem pela Universidade Estadual de Maringá (UEM), Docente do Curso de Medicina do Centro Universitário de Maringá (UniCesumar), Maringá, Paraná, Brasil.

ORCID: 0000-0002-8262-2086

\section{Marcelo da Silva}

Doutorando em Enfermagem pela Universidade Estadual de Maringá (UEM), Docente do Curso de Medicina do Centro Universitário de Maringá (UniCesumar), Maringá, Paraná, Brasil.

ORCID: 0000-0002-0376-0430

\section{INTRODUÇÃO}

0 trauma na física é definido como um fenômeno danoso decorrente de uma determinada energia que excedeu o limite suportável pelo organismo ${ }^{(1)}$. Saber qualificar e classificar a gravidade de um trauma no suporte pré-hospitalar é determinante para o seguimento no suporte hospitalar, pois possibilita melhores resultados no tratamento ${ }^{(2)}$. No cotidiano, é possível observar que as lesões estão relacionadas com determinados tipos de traumas, o que auxilia no tratamento da vítima ${ }^{(3)}$.

Nas últimas décadas, diversas instituições como Organização das Nações Unidas (ONU) e a Organização Mundial da Saúde (OMS) identificam os acidentes de trânsito como um problema mundial de saúde pública, devido ao número de vítimas com sequelas temporárias e permanentes, assim como o número de óbitos. A quantidade de mortes por esse motivo, no mundo, anualmente, passa de um milhão, com maior destaque para os países em desenvolvimento. Nove em cada dez mortes acontecem nos países mais pobres, e o Brasil ocupa uma colocação preocupante nesse quadro, já que se encontra entre as primeiras posições ${ }^{(4)}$.
O perfil epidemiológico das vítimas de acidentes de trânsito é composto, em sua maioria, por homens, adultos jovens, motociclistas, negros e com nível de escolaridade baixo. De acordo com a OMS, esse grupo (mais do que qualquer outro analisado) apresenta um risco maior de sofrer acidente de transporte terrestre (ATT) e, consequentemente, de óbito ${ }^{(4)}$.

Além disso, os acidentes de trânsito provocam outras consequências além da física, como problemas emocionais, financeiros, sociais, mentais, tanto para a vítima quanto para seus familiares ${ }^{(5)}$.

A taxa de anos de vida perdidos para mortes ou incapacidade em decorrência de ATT do Brasil, se comparado a outros países da América do Sul, insere o país na segunda colocação (1.230/ 100 mil habitantes), à frente de Bolívia e Equador, países com índice de desenvolvimento inferior ao do Brasil, e atrás apenas do Paraguai $(1.270 / \text { mil habitantes })^{(6)}$. Os elevados números de acidentes de trânsito no perímetro urbano, no Brasil, revelam um fator cultural, visto que o brasileiro tem pouco apreço pelas leis de trânsito. Assim, ele acredita ser proprietário das ruas e rodovias, não necessita obedecer às leis e despreza a existência de outros cidadãos que também fazem uso das vias. Ligada a esse comportamento está a atribuição de poder que foi estabelecida ao uso do veículo automotor $^{(4)}$.

Segundo o Instituto de Pesquisa Econômica Aplicada (IPEA), desde 1998, com a implementação do novo código de trânsito brasileiro e a criação de leis federais complementares mais rigorosas, como a Lei Seca, o Brasil ocupa uma situação muito mais confortável no âmbito legal em relação a outros países, no tocante à contenção de infrações. Isso porque existem inúmeras leis referentes ao uso de dispositivos de segurança, à utilização de substâncias associadas à direção, aos limites de velocidade impostos nas rodovias, entretanto a falta de punição para os motoristas transgressores é algo recorrente no país ${ }^{(4)}$.

Para prevenir os ATT, é necessário conhecer o perfil epidemiológico das vítimas, os transportes envolvidos, os tipos de lesões relacionadas com os tipos de acidentes, as áreas suscetíveis a acidentes ${ }^{(7)}$.

Entre as principais causas de acidentes de trânsito estão velocidade incompatível, ultrapassagem indevida, defeito mecânico em veículo, defeito na via, desobediência à sinalização, sonolência, falta de atenção, animais na pista, ingestão de ál- 


\section{artigo}

Albertini, A.B.N.; Garcia, T.V.; Paulo, L.G.; Toledo, E.R.S.; Charlo, P.B.; Silva, M.;

Caracterização epidemiológica e sociodemográfica de acidentes de trânsito: uma revisão integrativa da literatura

cool, não manutenção da distância de segurança, entre outras. Causas que podem ser solucionadas com campanhas de educação no trânsito e rigorosa fiscalização. Essas campanhas devem conhecer bem seu público-alvo e encontrar os melhores meios para alcançá-lo, de maneira constante e satisfatória, e devem ser divulgadas constantemente para que possam ser observados resultados ${ }^{(8)}$.

Os acidentes de trânsito precisam ser vistos como ocorrências capazes de serem evitadas e não como fatalidades comumente presentes. Assim, atingir os cidadãos para a adoção de medidas protetivas e seguras é uma tarefa árdua, a qual requer esforço, persistência e uma mudança de comportamento e de mentalidade por parte da população e dos governantes $^{(7)}$.

Nesse sentido, este estudo possui o seguinte questionamento: Quais as evidências disponíveis sobre os aspectos epidemiológicos, socioeconômicos e demográficos dos acidentes de transporte terrestre no Brasil? Com esse trabalho, pretende-se identificar, na produção científica existente, as causas associadas aos acidentes de trânsito, envolvendo os acidentes terrestres; verificar características epidemiológicas e clínicas de vítimas de traumas, bem como os impactos resultantes; identificar o perfil socioeconômico, demográfico e psicossocial das vítimas de trauma.

\section{METODOLOGIA}

Para o alcance do objetivo, optou-se pelo método da revisão da literatura científica na medida em que essa modalidade possibilita sumarizar as pesquisas já concluídas e obter conclusões a partir de um tema de interesse.

A coleta de dados foi realizada no período de 13 de agosto a 22 de outubro de 2019. Realizou-se pesquisa eletrônica nas estratégias de busca SciELO Brasil (Scientific Electronic Library Online), LILACS (Centro Latino-Americano de Informação em Saúde) e nas universidades brasileiras. Adotaram-se, como critério de inclusão, artigos que contemplassem a problemática em estudo, que contivessem os descritores selecionados, publicados entre 2011 e 2019. Foram excluídos os artigos não publicados na íntegra. Os descritores utilizados com base no DeCS foram Saúde Pública; Ferimentos e lesões; Acidentes de trânsito. E a revisão foi adaptada no modelo do PRISMA.

Inicialmente, a partir da leitura de títulos e resumos, selecionaram-se 52 obras, das quais se realizou a leitura na íntegra para verificar os critérios de elegibilidade e a proximidade com o tema, restando como amostra final 20 artigos, dos quais 18 foram publicados em português (Brasil), 1 em inglês e $1 \mathrm{em}$ português (Portugal). Após a seleção e leitura dos artigos, pre- encheu-se um formulário eletrônico, construído especificamente para esta pesquisa, com os seguintes dados: autores, título, periódico e ano de publicação.

Após a seleção dos artigos conforme os critérios de inclusão anteriormente determinados, no período de 04 de novembro de 2019 a 22 de maio de 2020, foram realizados os seguintes passos: leitura exploratória; seleção do material que compreenda os objetivos e tema deste estudo; análise detalhada dos textos; leitura interpretativa dos textos selecionados; redação do artigo.

Os resultados foram discutidos com a literatura. Por se tratar de estudo desenvolvido a partir de dados de domínio público, não foi necessário passar por apreciação ética.

A revisão integrativa foi validada duplamente por dois pesquisadores, Ana Beatriz Nakayama Albertini e Taísa Vieira Garcia a fim de confiabilidade dos dados.

\section{RESULTADOS}

Contemplaram o estudo, 20 artigos, dos quais 18 foram publicados na língua portuguesa (Brasil) e 1 na língua portuguesa (Portugal). Dos 20 trabalhos, 16 foram desenvolvidos no Brasil, 2 na Suíça, 1 em Portugal e 1 artigo foi publicado na língua inglesa, desenvolvido na Suíça. Das obras selecionadas, $90 \%(\mathrm{n}=18)$ são quantitativas e $10 \%(\mathrm{n}=2)$ qualitativas, conforme Tabela 1.

Tabela 1. Caracterização dos artigos selecionados para esta revisão integrativa, no período de 2011 a 2019. Brasil.

ID

A01

$\mathrm{AO2}$

$\mathrm{A03}$

$\mathrm{A04}$

A05

A06
Título

A letalidade dos acidentes de trânsito nas rodovias federais brasileiras em 2016*.

Motociclistas acidentados: caracterização, perfil comportamental e sintomas de transtornos mentais.

Maio amarelo: Contextualizando as estatísticas de acidentes de trânsito no Brasil.

Impacto do Código de Trânsito Brasileiro e da Lei Seca na mortalidade por acidentes de trânsito.

Global status report on road safety

Níveis de gravidade do trauma predição de sobrevida em vítimas de acidente de trânsito.

\section{Título do periódico}

Revista Brasileira de Estudos de População

Arquivos de Ciências da Saúde

DATASUS

Cadernos de Saúde Pública

World Health Organization (WHO).

Dissertação (Mestrado)
Ano

País

Idioma

2019 Brasil Português

2019 Brasil Português

2018 Brasil Português

2018 Brasil Português

2018 Suiça Inglês

2017 Brasil

Português 
$\mathrm{A} 07$

Acidentes de transporte terrestre: estudo Carga Global de Doenças, Brasil e unidades federadas, 1990 e 2015.

Relação entre o mecanismo de trauma e lesões diagnosticadas em vítimas de trauma fechado.

A09

Acidentes de transporte terrestre, não fatais, no Brasil: fatores associados e efeitos sobre a percepção do estado de saúde das vitimas.

Análise espacial dos acidentes de trânsito urbano atendidos

A10 pelo Serviço de Atendimento Móvel de Urgência: um recorte no espaço e no tempo.

Estimativa de sequelas físicas em vítimas de acidentes de

A11 transporte terrestre internadas em hospitais do Sistema Único de Saúde.

A12 Padrão de vítimas e lesões no trauma com motocicletas.

Prevalência e fatores associados a acidentes de trânsito com mototaxistas.

A14

Óbitos no trânsito urbano: qualificação da informação e caracterização de grupos vulneráveis.

Interpretação das lesões ortopédicas dos ocupantes dos veículos na reconstrução forense dos acidentes de viação.

A16 Acidentes de trânsito nas rodovias federais brasileiras.

Fatores associados, gravidade do trauma e sequelas de aci-

A17 dentes de transporte terrestre: um estudo a partir de egressos

A18

A19

A20

$$
\begin{gathered}
\text { Guia de Implantação e execução do PVT. } \\
\text { Relatório global sobre o estado da segurança viária. } \\
\text { Prevenção de lesões causadas pelo trânsito. Manual de } \\
\text { treinamento. }
\end{gathered}
$$

A partir dos artigos selecionados, foi possível observar que os acidentes de trânsito são responsáveis por uma parcela significativa de morbimortalidade em escala mundial. As lesões, as sequelas e as mortes por acidentes de transportes terrestres vêm se distribuindo de forma generalizada por todo o mundo, tornando o trauma e suas consequências alvo de grande preocupação.

Os acidentes de transporte terrestre configuram um problema de saúde pública, e o Brasil é um dos líderes no ranking com maior número de vítimas. Os ATT são a principal causa de morte de adultos jovens entre 20 e 29 anos, sobretudo os

\begin{tabular}{|c|c|c|c|}
\hline $\begin{array}{l}\text { Revista Brasileira de Epide- } \\
\text { miologia }\end{array}$ & 2017 & Brasil & Português \\
\hline $\begin{array}{c}\text { Revista do Colégio Brasileiro } \\
\text { de Cirurgiões }\end{array}$ & 2017 & Brasil & Português \\
\hline Tese (Doutorado) & 2017 & Brasil & Português \\
\hline $\begin{array}{l}\text { Revista Brasileira de Epide- } \\
\text { miologia }\end{array}$ & 2017 & Brasil & Português \\
\hline $\begin{array}{c}\text { Revista Brasileira de Epide- } \\
\text { miologia }\end{array}$ & 2016 & Brasil & Português \\
\hline $\begin{array}{l}\text { Revista da Faculdade de Ci- } \\
\text { ências Médicas de Sorocaba }\end{array}$ & 2016 & Brasil & Português \\
\hline $\begin{array}{c}\text { Revista Brasileira de Enfer- } \\
\text { magem }\end{array}$ & 2016 & Brasil & Português \\
\hline Cadernos de Saúde Pública & 2015 & Brasil & Português \\
\hline $\begin{array}{l}\text { Revista Portuguesa de Orto- } \\
\text { pedia e Traumatologia }\end{array}$ & 2015 & Portugal & Português \\
\hline IPEA & 2015 & Brasil & Português \\
\hline Tese (Doutorado) & 2015 & Brasil & Português \\
\hline Ministério da Saúde & 2015 & Brasil & Português \\
\hline OMS & 2015 & Suiça & Português \\
\hline $\begin{array}{l}\text { Organização Mundial da } \\
\text { Saúde (OMS) }\end{array}$ & 2011 & Suiça & Português \\
\hline
\end{tabular}
do sexo masculino. Além dos óbitos, eles são responsáveis por gerar sequelas temporárias e permanentes, inúmeros danos psíquicos e financeiros, sofrimento à vítima e aos familiares, um imenso custo aos cofres públicos e a sobrecarga do sistema de saúde.

Além disso, o aumento dos acidentes envolvendo motocicletas destaca-se como um obstáculo que necessita da devida atenção governamental. $\mathrm{O}$ crescimento da frota de motos, o valor mais acessível para aquisição e manutenção do veículo, o fato de ser muito utilizada como fonte de renda, a maior exposição corporal e o perfil dos condutores (na grande maioria, jovens, solteiros e com baixa renda e escolaridade) são fatores que contribuem para o grande aumento de acidentes e óbitos envolvendo essa categoria de transporte.

Outro fator relevante encontrado nos acidentes envolvendo motocicletas é a influência do estado emocional do condutor. Foram identificadas associações com alguns transtornos, como altos níveis de irritabilidade, inclinações antissociais, condutas envolvendo falta de responsabilidade, transtornos de ansiedade e depressão, entre outros.

Em relação à letalidade dos ATT, a colisão frontal e os atropelamentos destacam-se com o maior índice de mortalidade. E entre as vítimas mais vulneráveis estão os pedestres, os ciclistas e os motociclistas (esses últimos se tornaram os mais ameaçados, e a motocicleta ocupa a categoria de transporte mais fatal).

Outrossim, é importante evidenciar que o Nordeste é a região com maior ocorrência de óbito decorrente de ATT, em seguida estão Norte, Centro-Oeste e Sul. O Sudeste representa a região com menor mortalidade por ATT. Quanto aos dias e horários, os finais de semana e as madrugadas são responsáveis pelas circunstâncias mais letais.

Acerca das características das lesões, 


\section{artigo}

Albertini, A.B.N.; Garcia, T.V.; Paulo, L.G.; Toledo, E.R.S.; Charlo, P.B.; Silva, M.;

nos ATT envolvendo motocicletas, as vítimas sofrem mais comumente lesões com acometimento em extremidades, já nas vítimas de atropelamento, frequentemente se observam traumas em diversos segmentos corporais, por fim, nas vítimas de acidentes com automóveis, a lesão no segmento torácico é o mais comum.

É preciso salientar que entre as principais causas desses acidentes está a negligência dos condutores, os quais muitas vezes são imprudentes e infringem as leis do trânsito, pois utilizam alta velocidade, fazem o uso inadequado dos equipamentos de segurança e associam álcool ou drogas à direção.

Além disso, foi possível identificar uma relação entre o maior índice de acidentes envolvendo o sexo masculino e um fator sociocultural, no caso, a cultura machista impregnada na sociedade brasileira. Isso porque o homem, muitas vezes, vê-se em uma posição de poder, superioridade e invencibilidade, desta forma, coloca-se em situações risco.

Inegavelmente, após a implantação, em 1998, do Código de Trânsito, as mortes por acidente de trânsito diminuíram consideravelmente. E com o advento da Lei Seca, que entrou em vigor em 2008, o número de acidentes causados por condutores alcoolizados foram reduzidos, no entanto, continua alto considerando-se a gravidade do fato.

Sendo assim, é preciso considerar a formulação e adesão de políticas públicas já existentes para reduzir os ATT. Para ilustrar tem-se a Agenda 2030, criada pela Assembleia Geral das Nações Unidas, que visa uma redução de $50 \%$ das mortes e lesões causadas pelo trânsito até esse ano de 2020, por meio da intervenção rigorosa nos principais fatores de risco para os acidentes de trânsito. E o Brasil conta o Projeto Vida no Trânsito, que objetiva a melhoria dos sistemas de informação e, assim como a Agenda 2030, também tem o objetivo de interferir nos fatores causais mais relevantes dos ATT.

Entretanto, mesmo com tais ações em curso, os números desses trágicos desfechos necessitam de uma redução mais sig- nificativa. Por isso, as categorias públicas precisam conceder uma atenção especial para esse entrave, melhorando o rigor na aplicação das leis, na fiscalização, na educação dos condutores e também na segurança das vias.

\section{DISCUSSÃO}

Em termos de conceito, segundo o Instituto de Pesquisa Econômica Aplicada (IPEA) $)^{(8)}$, os acidentes de trânsito são definidos como choques entre veículos ou com objetos e locais fixos, atropelamentos, quedas de pedestres e ciclistas e capotamentos, com danos físicos, psicológicos e materiais. Esse episódio deve ocorrer em via pública, local de fluxo de veículos e pedestres. Já o Código Internacional de Doenças (CID-10) considera acidentes com veículo que ocorrem em via pública, que pode ser estrada, rua ou calçada, com circulação permitida para pessoas ou bens.

Nas últimas décadas, os acidentes de trânsito têm ganhado destaque em todo o mundo devido aos elevados números de óbitos, lesões e incapacidades, além das consequências emocionais, financeiras e sociais, o que fez ligar um sinal vermelho para esses números. O Brasil ocupa a quinta colocação no ranking entre os países com o maior número de vítimas de acidentes no trânsito, atrás somente da China, Índia, Rússia e Estados Unidos, ou seja, de países com uma população superior à do Brasil $^{(7)}$.

De acordo com Rocha ${ }^{(2)}$, o número de vítimas de acidentes de transporte terrestre (ATT), sejam elas vítimas fatais ou com sequelas provisórias ou permanentes, é significativo e vem se alastrando em escala mundial, independentemente da situação financeira de cada país. Consequentemente se apresenta como um dos principais problemas de saúde, deste século, a ser enfrentado.

Segundo o DATASUS, morrem aproximadamente 43 mil pessoas por ano no Brasil vítimas do trânsito. Os dados de 2015 do Ministério da Saúde (MS) indicam a ocorrência de 38.651 mortos. Andrade; Jorge ${ }^{(5)}$ afirma que, depois da implantação, em 1998, do Código de Trânsito, o número de mortes por acidente de trânsito diminuiu. Na última déca$\mathrm{da}$, esse índice voltou a crescer, mas ainda é menor em comparação aos números do início dos anos 90. De acordo com Ladeira et al.$^{(6)}$, observando cada grupo individualmente, nota-se que a queda no número de mortes não ocorreu homogeneamente, pois enquanto o número de óbitos entre os pedestres e ocupantes de veículo diminuiu, o número de vítimas fatais entre os motociclista e ciclistas aumentou.

As principais causas apontadas para esse desfecho trágico são: desorganização do trânsito; precariedade das vias e veículos; comportamento dos condutores, que inclui imprudência, infração às leis, uso inadequado de equipamentos de segurança (capacete, cinto de segurança), uso de álcool e outras substâncias psicoativas associados a puniçóes pouco rigorosas. Uma demonstração disso é um dado de 2017 da OMS, o qual aponta que uma em cada três mortes no trânsito que acontecem no mundo se deve ao excesso de velocidade. Todas essas motivações são ainda mais evidentes em países em desenvolvimento, como o Brasil. Paixão et. al. ${ }^{(7)}$ revela que o aumento da frota de veículos, visto em muitos países que tiveram uma melhora nas condições de vida da população, não seguido de um planejamento viário para suportar esse acréscimo colaborou com a elevação dos acidentes.

O Brasil apresenta, como responsáveis pelos acidentes, fatores como um planejamento urbano deficitário, a falta de fiscalização das vias e dos veículos, o descaso com a manutenção das rodovias, a impaciência do cidadão no trânsito ${ }^{(9)}$. Outra razão a ser considerada é o não uso de equipamentos de segurança de forma correta, como o capacete afivelado e com a viseira fechada, e o descaso com o cinto de segurança dos carros, tanto pelos passageiros da frente quanto pelos de trás, e com os dispositivos para crianças, de acordo com a idade, instalados incorretamente $e^{(2)}$.

Seguindo esse raciocínio, Medeiros ${ }^{(9)}$ afirma que: 
$\mathrm{Na}$ literatura o fator humano tem sido o principal elemento nas ocorrências de ATT, pois os demais o influenciam e ele exerce dominio apenas sobre o veículo. Entretanto, o humano tem sido o mais evidenciado, à vista de dirigir, por vez, sob efeito de álcool, com inexperiência na direção, cansado em descumprimento as leis de trânsito e velocidade excessiva. Contudo, os fatores relacionados à via abrangem os problemas de preservação das ruas e estradas, ausência de sinalização e iluminação insuficiente, e os com relação ao veículo incluem a falta de manutenção preventiva e o tipo de veículo.

Anexado a tal ideia, os acidentes são mais frequentes em pista simples em relação à dupla, e muitas vias não possuem algum tipo de barreira física separando as pistas. E entre os tipos de acidentes, as colisões frontais prevalecem ${ }^{(10)}$.

Apesar dos problemas enfrentados no Brasil, no relatório sobre o status global da segurança no trânsito da OMS, de 2015, citado por Ladeira et al.(6), em relação à legislação acerca do uso dos equipamentos de segurança, como cinto, uso de capacetes, equipamentos para transporte de menores, o Brasil ocupa uma posição superior se comparado aos outros países populosos. As leis brasileiras relacionadas à associação do consumo de álcool e direção também são rígidas quando comparadas a de outros países.

Além de responsáveis por um alto índice das mortes no país, os ATT provocam um grande impacto na vida da vítima e de seus familiares, já que muitas vezes essa vítima se torna dependente financeiramente e incapaz de realizar as atividades de vida diária, necessitando de ajuda. Segundo Andrade; Jorge ${ }^{(5)}$, os acidentes de transporte ocasionam inestimáveis danos emocionais, mentais e socioeconômicos, que incluem as faltas no trabalho, sofrimento à vítima e à família pela perda de produtividade ou anos de vida perdidos, além disso, pode provocar transtorno de estresse pós- -traumático, uma condição grave que gera incapacidade.

Paixão et al.$^{(7)}$ reafirma as imensuráveis perdas psicológicas, físicas, sociais e materiais aos envolvidos, além das despesas previdenciárias. Um estudo realizado em Bangladesh demonstrou que as famílias pobres apresentam maiores chances em perder o provedor da família em acidentes de trânsito do que as famílias em situações melhores de vida. A ausência do chefe da família acarreta implicações devastadoras na vida financeira da família, envolvendo a perda dos rendimentos, despesas médicas, funerárias e legais. A maioria das famílias retrataram uma redução na qualidade de vida, renda, gastos com alimentação ${ }^{(11)}$.

Dados do relatório publicado pelo Ipea ${ }^{(8)}$ demonstram que os acidentes nas rodovias brasileiras causam graves consequências ao sistema de saúde e à economia. No ano de 2014, ocorreram em torno de 170 mil acidentes nas rodovias federais brasileiras, os quais geraram um gasto de 12,3 bilhões de reais: $64,7 \%$ desses gastos foram associados à vítima, incluindo, cuidados com a saúde e perda de produção por lesão ou morte, e 34,7\% foram associados aos veículos, danos matérias e perdas de cargas.

Considerando toda a malha rodoviária, a estimativa de custos anuais no país é de aproximadamente 40 bilhões de reais, e nas áreas urbanas, 10 bilhões. Sendo assim, sobrecarregam os serviços de urgência e emergência, pois cerca de um quarto dos atendimentos por causas externas são por acidentes de trânsito, sobrecarregam também os serviços de especialidades e reabilitação de sequelas e de assistência social ${ }^{(7)}$.

Ao analisarmos as características epidemiológicas e o perfil das vítimas dos acidentes de trânsito, é possível reconhecer um padrão: segundo o DATASUS, $82,38 \%$ das vítimas de acidentes fatais são homens e $17,62 \%$ são mulheres; a maior parte dessas vítimas são adultos jovens, com idade entre 20 e 49 anos e proprietários de motocicletas. Segundo Simoneti et al. ${ }^{(12)}$, "O perfil de $49,6 \%$ das vítimas é de faixa etária predominante entre 20 a 29 anos, sendo que o gênero masculino representou aproximadamente $80 \%$ deste grupo etário".

Para Mendonça; Silva; Castro ${ }^{(4)}$, o retrato das vítimas de ATT é decorrente de condutas inadequadas tomadas principalmente por indivíduos jovens do sexo masculino ligadas a aspectos culturais e sociais. Essas atitudes levam essa parcela da população a se expor a situações de risco, tornando-a mais propícia a sofrer algum tipo de acidente. Corroborando essa ideia, nos últimos anos, esse tem sido o perfil das vítimas de ATT, homens, adultos jovens

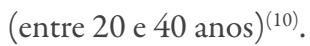

Beceiro et al. ${ }^{(13)}$ demonstra, em seu estudo que analisou acidentes envolvendo motocicletas, a maior incidência em homens, jovens, solteiros, trabalhadores, com níveis inferiores de escolaridade e baixa renda familiar. Além disso, metades das vítimas que relataram uso de bebida alcóolica, assumiram associá-lo à direção.

"Fatores socioculturais (machismo, relações de poder, competitividade, agressividade, dentre outros) que estabelecem o comportamento masculino na sociedade podem estar relacionados à maior exposição a situações de danos à saúde"(5). "As taxas de mortalidade por ATT foram 4 vezes maiores nos homens, sendo esse risco maior em todos os tipos de vítimas $-7,5$ vezes em ocupantes de motocicleta e 3,4 vezes em ocupantes de veículos a motor (dados não mostrados)"(6).

Em relação aos fatores comportamentais, Beceiro et al. ${ }^{(13)}$, assevera que o estado emocional dos condutores tem uma influência relevante nos acidentes e pode ser demonstrado com inclinações antissociais, desajuste pessoal e social, personalidade de dependência, irritabilidade, pensamentos negativos, autoconfiança diminuída, falta de responsabilidade, atribuindo-a a terceiros e fontes externas. Em seu estudo, verificou a existência de transtornos mentais nos motociclistas vítimas de acidentes, entre os principais encontrados estão transtornos depressivos, de ansiedade, de personalidade antissocial, dependência, somáticos, déficit de atenção, hiperatividade.

Rocha $^{(2)}$ expõe, na caracterização do 


\section{artigo}

Albertini, A.B.N.; Garcia, T.V.; Paulo, L.G.; Toledo, E.R.S.; Charlo, P.B.; Silva, M.;

perfil das vítimas, o nível de escolaridade: com maior tempo de estudo ${ }^{(9-11)}$, encontram-se os motociclistas, seguidos pelos ciclistas e usuários de outros tipos de veículos motorizados, com 5 a 8 anos de estudo, e por último, com 1 a 4 anos de estudo, estão os pedestres. Rocha aponta também que mais da metade das vítimas possuem uma renda entre 1 e 2 salários mínimos, e os ciclistas e motociclistas são em sua maioria responsáveis por prover os custos das despesas de suas famílias.

As análises epidemiológicas do IPEA ${ }^{(8)}$ explicitam a taxa de mortalidade dos mecanismos mais fatais de acidentes, entre eles a colisão frontal, que representou $33,7 \%$ das mortes, e os atropelamentos, que foram responsáveis por $14,6 \%$ das mortes. Esses dois tipos de acidentes responderam por $6,5 \%$ do total, e embora menos frequentes, foram os mais letais. Os acidentes resultantes de colisões frontais apresentam maior letalidade quando comparados às colisões traseiras ${ }^{(10)}$.

Reiterando essa ideia, Simoneti ${ }^{(12)}$ atesta que "O grupo das colisões representou a maior parcela das ocorrências, dentre os quais o envolvimento com carros se deu em $52,4 \%$ dos casos, seguidas de colisão com outras motos. A queda de motocicleta foi o segundo principal mecanismo de trauma, correspondendo a 15,4\%". "Outro resultado encontrado foi o risco maior de morte para os pedestres, seguidos pelos ciclistas e os ocupantes de motocicleta, em comparação aos ocupantes de automóveis" ${ }^{(10)}$. Entre os anos de 2000-2007, o maior número de óbitos pertencia aos pedestres, porém, nos últimos anos, os óbitos decorrentes de acidentes de motocicletas tornaram-se a principal causa de mortalidade no trânsito ${ }^{(9)}$.

Em relação a categoria de transporte, os automóveis provocam o maior número de acidentes, e também de mortes, nas rodovias em razão de ser a maior frota circulante. Em segundo lugar no número de acidentes estão as motocicletas, mas em nível de letalidade elas assumem o primeiro lugar. Demonstrando em dados, nos automóveis, a morte ou a lesão grave ocorrem a cada 8,3 acidentes, e nas moto- cicletas, esse número cai para 2,9. A explicação é a menor proteção oferecida nesse meio de transporte a qual deixa o usuário exposto $^{(8)}$.

De acordo com Simoneti et al. ${ }^{(12)}$, cerca de um quarto da frota de veículos no Brasil é composta por motocicletas. Esse número é consequência do preço considerado mais acessível e praticidade proporcionada pelo seu uso, entretanto possui apenas o capacete como proteção, ficando o resto do corpo sujeito a lesões. Como resultado, o usuário desse tipo de veículo apresenta maior número de lesões e morte.

Corroborando esse raciocínio, Carrapateira(1), afirma que "o Brasil apresenta número elevado de acidentes causados por motocicleta, provocado pela elevada produção de veículos desse tipo, economicamente mais acessíveis, e pela mobilidade que é proporcionada”. De acordo Medeiros $^{(9)}$, o aumento dos acidentes envolvendo essa categoria é decorrente de um conjunto de fatores, entre eles: o preço mais acessível desse tipo de veículo, o uso da motocicleta como uma fonte de renda, a mobilidade que ela oferece, gastos menores com a preservação do veículo em relação a outros tipos de veículos.

Reafirmando essa ideia, Ladeira et al.(6) expõe que o aumento de acidentes relacionados a motocicletas no Brasil se deve ao crescimento da frota desse tipo de veículo nos últimos anos em decorrência da melhora na condição financeira da população brasileira. Isso proporcionou a chance dessa parte da população adquirir seu veículo próprio, e a motocicleta, devido ao custo menor, é a escolha.

No que se refere à letalidade dos acidentes de transporte terrestre, foi possível observar que o tipo de transporte, a região, o tipo de pista, a idade da vítima, a hora e o dia da semana influenciam o número de óbitos. Segundo Carrapateira ${ }^{(1)}$, devido à falta de uma estrutura física que conceda proteção adequada, as motocicletas ocupam o primeiro lugar entre os veículos envolvidos em acidentes de trânsito, e, por deixarem seus condutores mais expostos, lesões graves são comuns.

Segundo o Ministério da Saúde, aci- dente com motocicleta é primeira causa específica de óbito por ATT no Brasil desde 2010, e a região Nordeste se destaca a nível nacional, mediante o significativo aumento das taxas de mortalidade e internação de motociclistas $^{(9)}$. Andrade; Jorge ${ }^{(5)}$ aponta que, nas últimas décadas, as motocicletas ocasionaram a maior taxa de mortalidade em decorrência de um aumento da frota.

Com relação aos veículos fechados, conforme Rocha ${ }^{(2)}$, esses apresentam números de vítimas superior a outros tipos de veículos assim como maior número de mortes na localidade onde ocorreu o acidente. Isso se deve ao fato de os veículos fechados possuírem uma quantidade superior de lugares juntamente com a imprudência dos motoristas e o não uso de dispositivos de segurança.

As chances de um acidente acabar em óbito são maiores no Nordeste, seguido pelo Norte, Centro-Oeste e Sul, e no Sudeste é menos provável. Já em relação aos dias da semana, a letalidade é maior nos finais de semana em comparação aos dias da semana. Quanto ao horário, as madrugadas apresentam maior letalidade em relação aos acidentes que ocorrem de noite e durante o dia. No tocante ao tipo de solo, o rural é mais letal que o urbano, e a respeito do tipo de pista, a fatalidade é menor na reta se comparada às curvas, assim como, nas pistas duplas, é também menor em relação às pistas simples. Quanto ao tipo de colisão, a frontal mostra-se mais letal que a traseira ${ }^{(10)}$.

Os finais de semana mostraram números mais elevados em relação aos dias da semana em decorrência do uso de álcool e outras substâncias ${ }^{(1)}$. Na questão da letalidade, Paixão et al. ${ }^{(7)}$, afirma que:

Nas três principais categorias de "usuários da via", observou-se que entre os 45 ocupantes de automóvel, $82 \%$ morreram nas primeiras 24 horas, sendo $60 \%$ no próprio local do acidente, ou seja, na via pública. Dos 95 óbitos de ocupantes de motocicletas, $74 \%$ ocorreram nas primeiras 24 horas após os aciden- 
tes de trânsito, e quase a metade (48\%) ocorreu em via pública. Apesar de $60 \%$ dos pedestres terem falecido nas primeiras 24 horas, nesse grupo, cerca de um terço dos óbitos ocorreu entre um e 29 dias (31\%). Mais da metade (53\%) dos ocupantes de bicicletas e de veículos pesados faleceram durante a internação hospitalar.

Em relação à prática diária dos acidentes de trânsito nos atendimentos de saúde, o mecanismo do trauma é um ponto importante a ser analisado, pois essa informação pode auxiliar na triagem, no diagnóstico e no tratamento do paciente, uma vez que muitas lesóes graves podem não se apresentar de forma grave instantaneamente.

Visto que é possível observar um padrão de lesão de acordo com o tipo de trauma, de forma generalizada, as vítimas de acidentes ocupantes de automóveis frequentemente apresentam lesão em tórax, devido ao choque direto nesse segmento. Já nos indivíduos que sofrem atropelamento, é comum a ocorrência de politraumas em diversas regióes do corpo, destacando o traumatismo crânio-encefálico. Nos motociclistas, as extremidades são mais acometidas ${ }^{(3)}$.

Beceiro et al. ${ }^{(13)}$ também demonstra que, em sua análise de acidentes motociclísticos, os segmentos corporais mais atingidos foram as extremidades e o abdome, destacando as lesões em extremidades como mais constantes e graves do que lesões de cabeça e face.

Uma vez que as lesões sofridas nos acidentes de trânsito geralmente obedecem a padrões de acordo com a categoria do veículo e com o modo da colisão, os acidentes envolvendo automóvel podem ser agrupados de forma generalizada pelo tipo de impacto, entretanto, existem diversas variáveis que podem influenciar e modificar esses padrões. Nos acidentes com choque frontal (o mais comum), as vítimas são projetadas para frente. A ausência do cinto de segurança faz com que haja um primeiro impacto dos joelhos contra o painel, o que pode causar lesões e fraturas nos joelhos, pés e tornozelos. Um segundo impacto contra o volante é capaz de provocar lesão no polegar ao segurar o volante, lesões abdominais e torácicas, que incluem fraturas de costelas, esterno e danos a órgãos vitais, como pulmão, coração, fígado. Por fim, um terceiro choque contra o para-brisas pode levar à ejeção da vítima, a fraturas e lesões ligamentares na coluna cervical, e o trauma da cabeça contra o para-brisas geralmente provoca lesões contusas em couro cabeludo e face. Quando se trata de um impacto lateral (segundo mais comum), geralmente os passageiros sofrem lacerações causadas pelos estilhaços dos vidros laterais, as fraturas de costelas são muito frequentes, o dano ou rompimento do fígado, baço e rins podem ocorrer de acordo com o lado da batida. Já nos acidentes envolvendo capotamentos, não há um padrão característico, na ausência do uso de cinto de segurança, grande parte das vezes ocorrem inúmeras lesões e traumatismos em diversos segmentos corporais, além disso, podem acontecer ejeções. Por último, em choques com impacto traseiro, as lesões mais comuns são as ligamentares e discais oriundas de uma hiperextensão do pescoço ${ }^{(14)}$.

Considerado um problema de saúde pública, os ATT correspondem a uma das principais causas de morte, sendo a principal em jovens de 15 a 29 anos, além das graves repercussões para as vítimas, familiares, sistema de saúde e economia. Objetivando diminuir esses números, na Assembleia Geral da Nações Unidas de 2015, foi lançada a Agenda 2030, e incluiu-se como meta dos Objetivos de Desenvolvimento Sustentável uma redução de $50 \%$ das mortes e traumatismos causados pelo trânsito até 2020. Para que essa meta seja alcançada, é fundamental aplicação rigorosa das leis de trânsito, em especial as que se referem aos principais fatores de risco para os acidentes, que são excesso de velocidade, direção associada ao uso de álcool e outras drogas, ausência do uso de equipamentos de proteção, como capacetes, cintos de segurança e dispositivos de segurança para crianças. Além disso, visto que a maioria dos países não respeitam os padrões mínimos de segurança nos veículos, é essencial o fornecimento de um modelo seguro para os novos carros fabricados, uma vez que são capazes de evitar os choques e diminuem as chances de lesões graves ${ }^{(15)}$.

No Brasil, o Ministério da Saúde auxilia os estados e municípios na implementação de intervenções de vigilância e prevenção de mortes e traumas causados pelo trânsito. Exemplo disso é o programa Projeto Vida no Trânsito. Entre os propósitos do projeto, estão a otimização dos sistemas de informações, atendimento às vítimas e, assim como a OMS, ele objetiva intervir de forma direcionada nos principais fatores de risco, como velocidade inadequada, consumo de álcool e drogas e mau uso dos dispositivos de segurança. Essa proposta se iniciou em 2011 em cinco capitais de cada região e subsequentemente foi estendida para todo o país ${ }^{(16)}$.

\section{CONCLUSÃO}

A partir dos resultados deste estudo, podem-se identificar as principais características epidemiológicas, socioeconômicas, demográficas e psicossociais envolvidas nos acidentes de transporte terrestre. As vítimas mais suscetíveis aos ATT são jovens do sexo masculino. É possível verificar também uma associação com níveis econômicos e educacionais inferiores e perturbações no estado emocional do condutor.

Constatou-se, ainda, que as motocicletas constituem a categoria de transporte mais letal nos últimos anos. Esse fato pode ser atribuído, principalmente, ao aumento da frota, ao valor mais acessível, à utilização como fonte de renda e ao perfil dos usuários, que habitualmente são jovens do sexo masculino, um perfil geralmente relacionado a maior envolvimento em situações de risco.

Em relação à letalidade, a região com maior número de mortos por ATT é o Nordeste. E o período de maior incidên- 


\section{artigo}

Albertini, A.B.N.; Garcia, T.V.; Paulo, L.G.; Toledo, E.R.S.; Charlo, P.B.; Silva, M.

Caracterização epidemiológica e sociodemográfica de acidentes de trânsito: uma revisão integrativa da literatura

cia são os finais de semana e durante as madrugadas, fatores que estabelecem estreita associação com uso de álcool e outras drogas.

As consequências desses ATT são de- vastadoras. Para a vítima, há o óbito e, quando esse não ocorre, os indivíduos que sobrevivem podem manifestar sequelas físicas e psicológicas graves. Além disso, tem-se os familiares, que sofrem com perdas afetivas e muitas vezes também econômicas. A saúde pública e a economia, por sua vez, padecem com uma sobrecarga e com altos custos anuais, respectivamente.

\section{REFERÊNCIAS}

1. Carrapateira LC. Níveis de gravidade do trauma e predição de sobrevida em vítimas de acidente de trânsito. 2017. 56 f. Dissertação (Mestrado) - Curso de Saúde e Desenvolvimento na Região Centro-Oeste, Universidade Federal do Mato Grosso do Sul, Campo Grande, 2017.

2. Rocha GS. Fatores associados, gravidade do trauma e sequelas de acidentes de transporte terrestre: um estudo a partir de egressos hospitalares. 2015. 288 f. Tese (Doutorado) - Curso de Saúde Pública, Universidade de São Paulo Faculdade de Saúde Pública, São Paulo, 2015.

3. Parreira JG, Rondini GZ, Below C, TANAKA GO, Pelluchi JN, Arantes-Perlingeiro J, Soldá SC, Assef JC. Relação entre o mecanismo de trauma e lesões diagnosticadas em vítimas de trauma fechado. Revista do Colégio Brasileiro de Cirurgiões, [s.l.], v. 44, n. 4, p. 340-347, ago. 2017. FapUNIFESP (SciELO). http://dx.doi. org/10.1590/0100-69912017004007.

4. Mendonça MFS, Silva APSC, Castro CCL. Análise espacial dos acidentes de trânsito urbano atendidos pelo Serviço de Atendimento Móvel de Urgência: um recorte no espaço e no tempo. Revista Brasileira de Epidemiologia, [s.I.], v. 20, n. 4, p.727-741, dez. 2017. FapUNIFESP (SciELO). http://dx.doi.org/10.1590/19805497201700040014.

5. Andrade SSCA, Jorge MHPM. Estimativa de sequelas físicas em vítimas de acidentes de transporte terrestre internadas em hospitais do Sistema Único de Saúde. Revista Brasileira de Epidemiologia, [s.I.], v. 19, n. 1, p. 100-111, mar. 2016. FapUNIFESP (SciELO). http://dx.doi.org/10.1590/1980-5497201600010009

6. Ladeira RM, Malta DC, Morais Neto OL, Montenegro MMS, Soares Filho AM, Vasconcelos CH, Mooney M, Naghavi M. Acidentes de transporte terrestre: estudo carga global de doenças, brasil e unidades federadas, 1990 e 2015. Estudo Carga Global de Doenças, Brasil e unidades federadas, 1990 e 2015. Revista Brasileira de Epidemiologia, [s.I.], v. 20, n. 1, p. 157-170, maio 2017. FapUNIFESP (SciELO). http://dx.doi.org/10.1590/19805497201700050013.

7. Paixão LMMM, Gontijo ED, Mingoti SA, Costa DAS, Friche AAL, Caiaffa WT. Óbitos no trânsito urbano: qualificação da informação e caracterização de grupos vulneráveis. Cadernos de Saúde Pública, v. 31, sup., p. S1-S15, 2015. Disponivel em: <https://www. scielosp.org/article/ssm/content/raw/?resource_ssm_path=/ media/assets/csp/v31s1/pt_0102-311X-csp-31-s1-0092. pdf>. Acesso em: 10 dez. 2018.

8. Instituto de pesquisa econômica avançada (IPEA). Impactos sociais e econômicos dos acidentes de trânsito nas aglomerações urbanas brasileiras. Relatório executivo, Brasília, 2003. JE-
SUS VF, Siqueira LG. Causas associadas aos acidentes de trânsito envolvendo motociclistas: revisão integrativa. Revista de Enfermagem do Centro-Oeste Mineiro. 2017;7:e1514. https://doi. org/10.19175/recom.v7i0.1514

9. Medeiros WMC. Acidentes de transporte terrestre, não fatais, no Brasil: fatores associados e efeitos sobre a percepção do estado de saúde das vítimas. 2017. 68 f. Tese (Doutorado) - Curso de Ciências da Saúde, Universidade Federal no Rio Grande do Norte, Natal, 2017.

10.Barroso Junior GT, Bertho ACS, Veiga AC. A letalidade dos acidentes de trânsito nas rodovias federais brasileiras. Revista Brasileira de Estudos de População, [s.l.], v. 36, p. 1-22, 16 jul. 2019. Associação Brasileira de Estudos Populacionais. http://dx. doi.org/10.20947/s0102-3098a0074

11.Mohan D, Tiwari G, Khayesi M, Nafukho FM. Organização Mundial da Saúde. Prevenção de lesões causadas pelo trânsito. Manual de treinamento, 2011. Disponivel em: https://bvsms. saude.gov.br/bvs/publicacoes/prevencao_lesao_causadas_ transito.pdf. Acesso em: 22 mar. 2020.

12.Simoneti FS, Cunha LO, Gurfinkel Y, Mancilha TS, Campioni FC, Cabral AH, Portella DL, Rodrigues JMS, Novo NF. Padrão de vítimas e lesões no trauma com motocicletas. Revista da Faculdade de Ciências Médicas de Sorocaba, [s.I.], v. 18, n. 1, p. 36-40, 1 mar. 2016. Portal de Revistas PUC SP. http://dx.doi.org/10.5327/ z1984-4840201624711.

13.Beceiro MF et al. Motociclistas acidentados: caracterização, perfil comportamental e sintomas de transtornos mentais: caracterização, perfil comportamental e sintomas de transtornos mentais. Arquivos de Ciências da Saúde, [s.l.], v. 26, n. 2, p. 125, 15 nov. 2019. Faculdade de Medicina de Sao Jose do Rio Preto - FAMERP. http://dx.doi.org/10.17696/2318-3691.26.2.2019.1443.

14.Durão CH, Lucas FM. Interpretação das lesões ortopédicas dos ocupantes dos veículos na reconstrução forense dos acidentes de viação. Revista Portuguesa de Ortopedia e Traumatologia, Lisboa, v. 23, n. 4, p. 298-309, abr. 2014.

15.Organização Mundial de Saúde (OMS). Relatório global sobre o estado da segurança viária, 2015. Genebra. Disponível em: https://www.who.int/violence_injury_prevention/road_safety_status/2015/Summary_GSRRS2015_POR.pdf. Acesso em: 21.nov 2019.

16.Ministério da Saúde (BR). Guia de Implantação e execução do PVT (2015). Brasília: Ministério da Saúde; 2015. Disponível em: https://www.saude.gov.br/vigilancia-em-saude/vigilancia-de-violencias-e-acidentes-viva/vigilancia-de-acidentes/transito. Acesso em: 15 jan. 2020. 